\title{
Hollow spheres of MCM-41 aluminosilicate with pinholes $\dagger$
}

\author{
Hong-Ping Lin, ${ }^{* a}$ Chung-Yuan Mou, ${ }^{b}$ Shang-Bin Liu ${ }^{a}$ and Chih-Yuan Tang ${ }^{c}$ \\ a Institute of Atomic and Molecular Sciences Academia Sinica, PO Box 23-166, Taipei, Taiwan 106. \\ E-mail:hplin@gcn.net.tw \\ ${ }^{b}$ Department of Chemistry and Center of Condensed Matter, National Taiwan University, Taipei, \\ Taiwan 106 \\ c Department of Zoology, National Taiwan University, Taipei, Taiwan 106
}

\section{Received (in Cambridge, UK) 24th May 2001, Accepted 8th August 2001 First published as an Advance Article on the web 19th September 2001}

\begin{abstract}
Hollow spheres of MCM-41 mesoporous aluminosilicates, with two small holes on the shell, have been synthesized from a surfactant-aluminosilicate gel composite.
\end{abstract}

Hollow spherical ceramic materials of micron size have received a lot of recent attention due to their potential applications in drug-delivery, adsorption, and catalysis. ${ }^{1-3}$ The standard approach for generating hollow spheres is to use organic polymer beads as the templates which control the size of the void volume. ${ }^{4,5}$ However, large entities such as macromolecules usually cannot penetrate such spheres because of the microporous shell. It would be desirable to leave a macro-hole on the shell surface for transporting macromolecules. Furthermore, a mesoporous shell of the hollow sphere would allow simultaneous embedding of smaller molecules.

In this paper, we report a liquid crystalline/sol-gel approach to the synthesis of vesicular mesoporous aluminosilicates MCM-41. Both the diameters of the hollow spheres and the aluminium content of the materials can be controlled. The vesicular hollow spheres of MCM-41 were reasonably supposed to possess a pair of holes of submicron size on exactly opposite sides.

The hollow spheres of MCM-41 aluminosilicates were prepared according to our previously reported delayed neutralization procedure at $27^{\circ} \mathrm{C}$. 6,7 Typically, the surfactant myristyltrimethylammonium bromide, $\mathrm{CH}_{3}\left(\mathrm{CH}_{2}\right)_{13} \mathrm{~N}\left(\mathrm{CH}_{3}\right)_{3} \mathrm{Br}$, $\left(\mathrm{C}_{14} \mathrm{TMAB}\right)$, as organic template, and butanol $(\mathrm{BuOH})$, as cosurfactant, were dissolved in sufficient water to form a clear solution. Sodium silicate was added and mixed thoroughly. Then $1.2 \mathrm{M} \mathrm{H}_{2} \mathrm{SO}_{4}(\mathrm{aq})$ was gradually added to adjust the $\mathrm{pH}$ value of the gel solution to $c a$.9.0. Finally, the gel solution was combined with the required amount of sodium aluminate $\left(\mathrm{NaAlO}_{2}\right)$. The molar ratios of the resulting gels were 1 $\mathrm{C}_{14} \mathrm{TMAB}: 1.50 \quad \mathrm{SiO}_{2}: 1.20 \quad \mathrm{NaOH}: 0.48 \quad \mathrm{H}_{2} \mathrm{SO}_{4}:(0.02-0.1)$ $\mathrm{NaAlO}_{3}:(1.25-1.85) \mathrm{BuOH}: 200 \mathrm{H}_{2} \mathrm{O}$. The vesicular sphere products were obtained by filtering the solution after hydrothermal treatment at $100{ }^{\circ} \mathrm{C}$ for $6 \mathrm{~h}$. After washing with deionised water, drying and calcination at $580{ }^{\circ} \mathrm{C}$ in air, hollow spheres of MCM-41 mesoporous aluminosilicate were obtained.

In Fig. 1(A), we see that the aluminosilicate spheres were produced in high yield $(\sim 95 \%)$ and uniform size $(5.0 \mu \mathrm{m})$. From some broken spheres (broken by the scraper during the SEM sample preparation process), one can easily distinguish that the micrometer-sized spheres are hollow (Fig. 1(B)). Without the use of sodium aluminate, we previously obtained hollow spheres with a center pillar inside. ${ }^{7}$ TEM micrographs (not shown here) of microtomed samples also show the hollow insides of the spheres. Careful checking under higher magnification showed that the surface of every hollow sphere contains a tiny hole of $c a .0 .1 \mu \mathrm{m}$ in diameter (Fig. 1(C)). The existence of this tiny hole would allow the large internal void space of the

$\dagger$ Electronic supplementary information (ESI) available: XRD pattern of a hollow sphere of MCM-41 (Si/Al = 30). See http://www.rsc.org/suppdata/ $\mathrm{cc} / \mathrm{b} 1 / \mathrm{b} 104600 \mathrm{~b} /$ sphere to be more accessible to larger entities such as viruses or macromolecules. An ultra-thin film microtome TEM micrograph of the shell of a hollow sphere is illustrated in Fig. 1(D). This enables the mesostructure of the shell to be examined and clearly shows the hexagonal-arrayed honeycomb mesostructures of MCM-41. This well-aligned structure is in agreement with its XRD pattern, which possesses 3-4 sharp peaks (see ESI $\dagger$ ). 8,9

To understand the direction of the nanochannels on the shell of the hollow sphere, we carefully observed the nanochannels near the tiny hole on the shell under a TEM. Fig. 2(A) clearly shows that the nanochannels of the hollow sphere of the MCM41 mesoporous aluminosilicates are arranged concentrically around the hole. Taking the hole as the north pole of the sphere, the nanochannels are arranged in the latitudinal direction to form the shell. This is in agreement with our previous observation that nanochannels arrange latitudinally in pillarwithin-spheres structures except that this time the center pillar is removed, leaving holes in the shell at the bases of the pillar. The
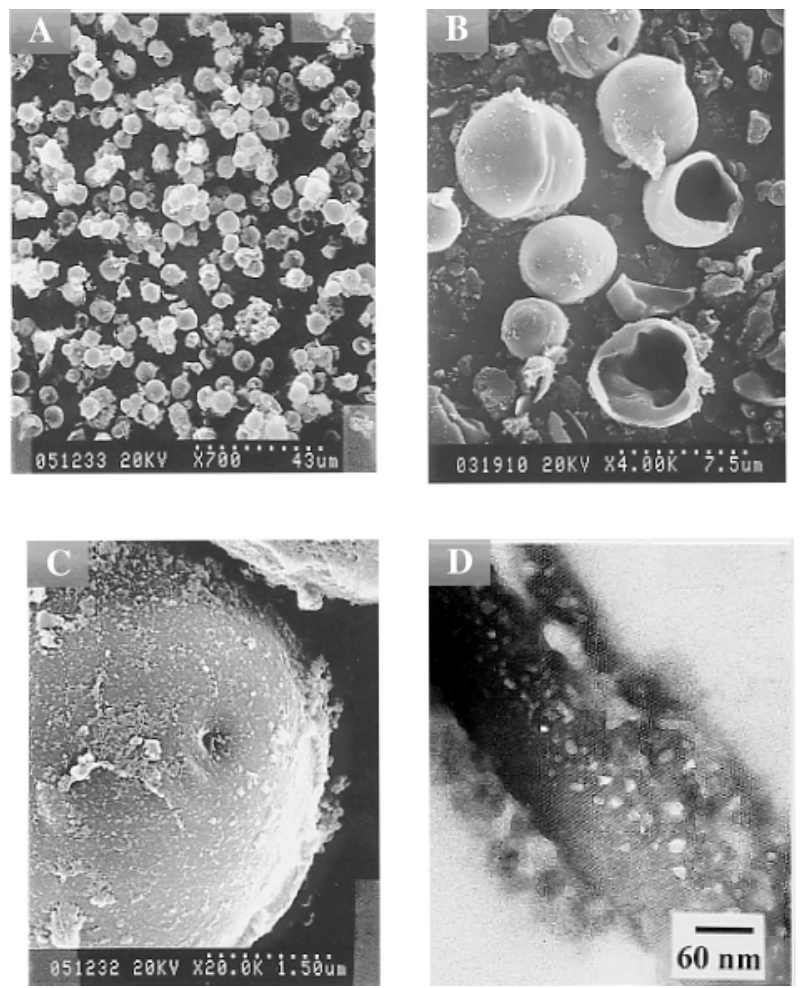

Fig. 1 SEM and TEM micrographs of the mesoporous aluminosilicate $(\mathrm{Si} / \mathrm{Al}=30)$ hollow spheres. (A) Low magnification SEM showing the uniform spheres with average diameter of $5 \mu \mathrm{m}$. (B) SEM of some broken hollow spheres of MCM-41 mesoporous aluminosilicates. (C) A tiny hole on the shell of the hollow sphere. (D) An ultra-thin section TEM picture displayings the well-ordered nanostructures of the vesicle-shaped aluminosilicate spheres. 

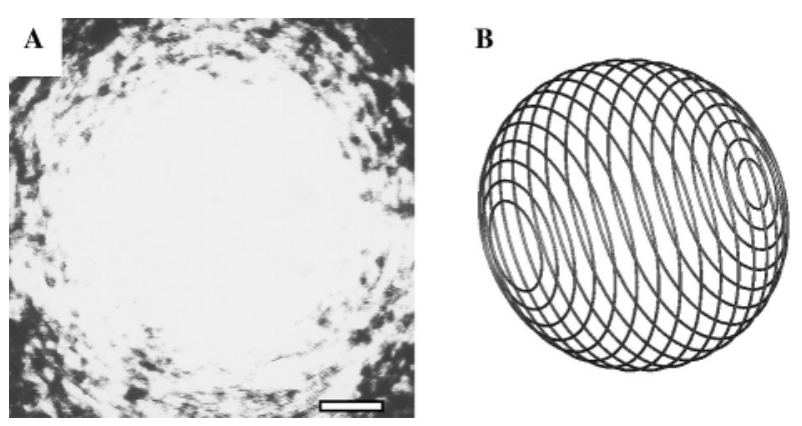

Fig. 2 (A) A HR-TEM micrograph showing nanochannels arranging around the tiny hole. The scale bar in this figure is $110 \mathrm{~nm}$. (B) A schematic diagram of the vesicle-like sphere of aluminosilicates MCM-41.

fact that we can always see only a single hole on the shell leads us to the logical conjecture that every hollow sphere possesses two tiny holes on opposite sides. A schematic diagram of the hollow sphere is shown in Fig. 2(B). Although a direct microscopic observation of both polar holes on a hollow sphere was not obtained, the existence of the tiny holes at both poles can be reasonably explained. The singularity at the pole gives too high an energy penalty to form closed hollow spheres. ${ }^{10,11}$ This hollow sphere with two tiny holes at both poles is a novel hierarchical structure that has not previously been identified. Compared with our previous pillar-within-sphere structure, ${ }^{7}$ the aluminium component apparently makes the center pillar position of higher energy and the aluminosilicate materials are deposited around the waist to make a thicker shell.

In addition to making hollow spheres with an $\mathrm{Si} / \mathrm{Al}$ ratio of 30 , we can prepare samples with different aluminium contents by simply adding different amounts of sodium aluminate. In the range $\mathrm{Si} / \mathrm{Al}=15-70$, hollow spheres of MCM-41 aluminosilicates with well-aligned mesostructures have been obtained. By examining the ${ }^{27} \mathrm{Al}$ MAS NMR spectra of the uncalcined hollow spheres, we found that only one peak at $54 \mathrm{ppm}$, referenced to a dilute aqueous solution of $\mathrm{Al}\left(\mathrm{NO}_{3}\right)_{3}$, was observed in each sample. This indicates that all the $\mathrm{Al}$ atoms are incorporated in the silica framework to form the hollow sphere. ${ }^{12}$

We can also control the size of the hollow spheres. In lyotropic surfactant liquid crystals, the rigidity of the surfactant assembly, such as the membrane, decreases with the amount of cosurfactant alkanol. ${ }^{13,14}$ Accordingly, we changed the $\mathrm{BuOH} /$ $\mathrm{C}_{14} \mathrm{TMAB}$ ratio in the reaction mixture. Fig. 3 demonstrates that the diameter of the hollow sphere decreases with an increase of the $\mathrm{BuOH} / \mathrm{C}_{14} \mathrm{TMAB}$ ratio, as we expected. However, the size range can be adjusted only in the range of 2.5 to $7.6 \mu \mathrm{m}$ using the $\mathrm{C}_{14} \mathrm{TMAB}-\mathrm{BuOH}$-aluminosilicate-water composition. Outside this range, the morphology will transform into fine particles or tubules-within-tubules structures. ${ }^{15}$ We found that

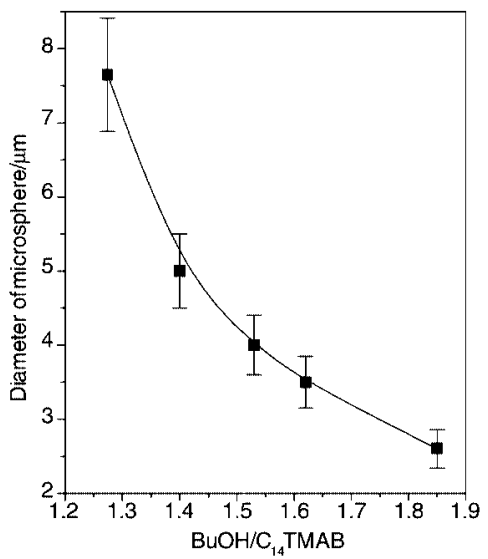

Fig. 3 The diameter of the hollow sphere of MCM-41 aluminosilicates as a function of the $\mathrm{BuOH} / \mathrm{C}_{14} \mathrm{TMAB}$ ratio.
Table 1 The physical properties of the hollow spheres of MCM-41 mesoporous aluminosilicates with different diameters and $\mathrm{Si} / \mathrm{Al}$ ratio composites

\begin{tabular}{|c|c|c|c|c|c|}
\hline $\begin{array}{l}\text { Diameter/ } \\
\mu \mathrm{m}\end{array}$ & $\mathrm{Si} / \mathrm{Al}$ & $\begin{array}{l}d_{100} \\
\text { value/nm }\end{array}$ & $\begin{array}{l}\text { Pore } \\
\text { size }^{a} / \mathrm{nm}\end{array}$ & $\begin{array}{l}\text { BET } \\
\text { surface } \\
\text { area/ } \\
\mathrm{m}^{2} \mathrm{~g}^{-1}\end{array}$ & $\begin{array}{l}\text { Porosity } \\
\mathrm{cm}^{3} \mathrm{~g}^{-1}\end{array}$ \\
\hline 7.5 & 30 & 3.25 & 2.25 & 960 & 0.67 \\
\hline 5.0 & 30 & 3.30 & 2.30 & 975 & 0.65 \\
\hline 2.8 & 30 & 3.32 & 2.23 & 1002 & 0.62 \\
\hline 5.0 & 60 & 3.42 & 2.28 & 996 & 0.70 \\
\hline 5.0 & 15 & 3.25 & 2.20 & 952 & 0.63 \\
\hline
\end{tabular}

$a$ The central value of the pore size distribution calculated from the $\mathrm{N}_{2}$ adsorption isotherm branch using the BJH method. ${ }^{b}$ The $\mathrm{N}_{2}$ adsorption value at $P / P_{0}=0.9$.

the tiny hole size ranges from $c a .0 .05-0.1 \mu \mathrm{m}$ and is not apparently dependent on sphere diameter.

Table 1 lists the physical properties of the hollow spheres with various diameters and $\mathrm{Al}$ contents. Comparing these data, the surface area, pore size and porosity are not significantly affected by the aluminium content or the diameter. For different $\mathrm{Al}$ contents and various sphere diameters, high yields of vesicular hollow spheres of MCM-41 materials with high surface area, uniform pore size and large porosity have been successfully synthesized using a simple self-organization approach.

The discovery of such an intricate hollow spherical topology with two tiny holes at the poles of the sphere will also be interesting to the physics of complex biomineralization processes. It will enrich our ability to build hierarchical complex inorganic-organic composite structures using the bottom-up approach.

This research was financially supported by the China Petroleum Co. and the National Science Council of Taiwan.

\section{Notes and references}

1 F. Carusco, Chem. Eur. J., 2000, 6, 413.

2 D. L. Wilcox, Sr., M. Berg, T. Bernat, D. Kelleman and J. K. Cochran, Jr., Hollow and Solid Spheres and Microspheres: Science and Technology Associated with their Fabrication and Application, MRS Proc., Pittsburgh, PA, 1994, vol. 372.

3 H. Huang, E. E. Remsen, T. Kowalewski and K. L. Wooley, J. Am. Chem. Soc., 1999, 121, 3805.

4 (a) Z. Zhong, Y. Yin, B. Gates and Y. Xia, Adv. Mater., 2000, 12, 206; (b) Y. Yin, Y. Lu, B. Gates and Y. Xia, J. Am. Chem. Soc., 2001, 13, 1146.

5 S. Mecking and R. Thomann, Adv. Mater., 2000, 12, 593.

6 (a) H. P. Lin and C. Y. Mou, Science, 1996, 273, 765; (b) H. P. Lin, S. Cheng and C. Y. Mou, Microporous Mater., 1997, 10, 111.

7 H. P. Lin, Y. R. Cheng and C. Y. Mou, Chem. Mater., 1998, 10, 3772 .

8 C. T. Kresge, M. E. Leonowicz, W. J. Roth, J. C. Vartuli and J. S. Beck, Nature, 1992, 359, 710.

9 D. Zhao, P. Yang, Q. Huo, B. F. Chmelka and G. D. Stucky, Curr. Opin. Solid State Mater. Sci., 1998, 3, 111.

10 (a) P. T. Tanev and T. J. Pinnavaia, Science, 1996, 271, 1267; (b) P. T. Tanev, Y. Liang and T. J. Pinnavaia, J. Am. Chem. Soc., 1997, 119 861.

11 D. Demus, J. Goodby, G. W. Gray, H. W. Spiess and V. Vill, Handbook of Liquid Crystals, Wiley-VCH, Weinheim, New York, 1998, vol. 1.

12 (a) M. T. Janicke, C. C. Landry, S. C. Christiansen, S. Birtalan, G. D. Stucky and B. F. Chmelka, Chem. Mater., 1999, 11, 1342; (b) Z. Luan, C. F. Cheng, H. He and J. Klinowski, J. Phys. Chem., 1995, 99, 10590.

13 H. P. Lin, Y. R. Cheng, S. B. Liu and C. Y. Mou, J. Mater. Chem., 1999, 9, 1197.

14 (a) H. Hoffmann, C. Thunig, U. Munkert, W. Meyer and W. Richer, Langmuir, 1992, 8, 2629; (b) E. Valenzuuela, E. Abiun and E. Lissi, J. Colloid Interface Sci., 1984, 102, 46.

15 K. M. McGrath, D. M. Dabbs, N. Yao, I. A. Aksay and S. M. Gruner, Science, 1997, 277, 552. 